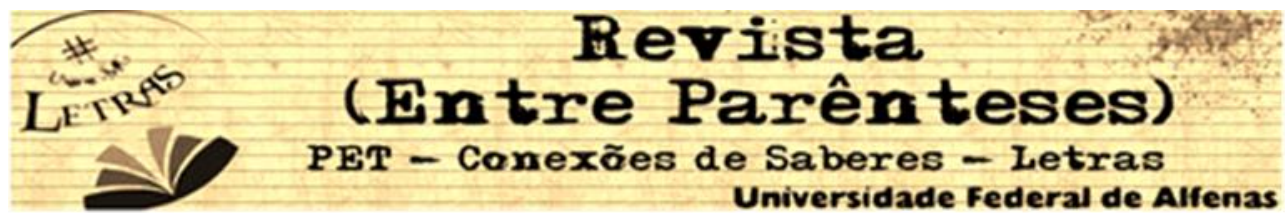

\title{
MEMORIALISMO: FICÇÃO, HISTÓRIA, LITERATURA REVISÃO TEÓRICO-CRÍTICA
}

\author{
Sheila dos Santos Silva ${ }^{1}$ \\ Universidade Vale do Rio Verde - UNINCOR \\ (sheilacax@hotmail.com)
}

\begin{abstract}
RESUMO: A narrativa de cunho memorialista tem forte tradição no Brasil, pelo menos desde fins do século XIX, com o Romantismo, quando começam a surgir os primeiros textos que se pautam pelo registro de eventos e de recordações relacionados à vida pessoal dos escritores e à sua inserção cultural e identitária na história de nosso país. Assim, pautamo-nos pela convicção de que memória, narrativa e história estão, no caso de obras de tradição memorialista, interligadas, não sendo possível definir com clareza as fronteiras que as delimitam ou restringem, o que impossibilita que sejam classificadas e compartimentadas em espécies de "caixas" isoladas. Partindo disso, o presente artigo visa apresentar uma reflexão acerca dos entrecruzamentos entre história, ficção e literatura em textos memorialísticos, abordando as considerações de Paul Ricoeur (2007), Benedito Nunes (1988), Valéria Gobbi (2004), Márcio Seligmann-Silva (2003) e Sandra Pesavento (2000) acerca do assunto.

Palavras-chave: Memória; Ficção; História; Literatura.
\end{abstract}

ABSTRACT: The memoirist narrative has a strong tradition in Brazil, at least since the end of the 19th century, with Romanticism, when the first texts start appearing they are based on the recording of events and memories related to the writers personal's life and their cultural insertion and identity in the history of our country. Thus, guided us by the conviction that memory, narrative and history are, in the case of works of memorialist tradition, interconnected, and it is not possible to clearly define the boundaries that delimit or restrict them, that makes it impossible to classified them and compartmentalized in species of isolated "boxes". From this, this article aims to present a reflection on the interrelations between history, fiction and literature in memorialistic texts, approach the considerations of Paul Ricoeur (2007), Benedito Nunes (1988), Valéria Gobbi (2004), Márcio Seligmann-Silva (2003) and Sandra Pesavento (2000) on the subject.

Keywords: Memory; Fiction; History; Literature.

Resumen: la narrativa de carácter memorialista tiene fuerte tradición en Brasil, al menos desde fines del siglo XIX, con el Romanticismo, cuando empiezan a surgir los primeros textos centrados en el registro de los eventos y recuerdos relacionados a la vida personal de los escritores y a su inserción cultural e identitaria en la historia de nuestro país. Así, nos orientamos por la convicción de que la memoria, narrativa e historia están, en el caso de obras de tradición memorialista, interconectadas, una vez que no es posible definir claramente las fronteras que las delimitan o restringen, lo que imposibilita que sean clasificadas y compartidas en especies de "cajas" aisladas. A partir de ello, el presente artículo tiene como propósito presentar una reflexión acerca de los entrecruces entre

1 Mestranda em Letras pela Universidade Vale do Rio Verde (UNINCOR). Este artigo deriva de minha pesquisa de mestrado em andamento, realizada sob orientação da Prof ${ }^{\mathrm{a}}$. Dra . Maria Elisa Rodrigues Moreira, intitulada Città di Roma: uma história de família costurada com os fios da memória. 


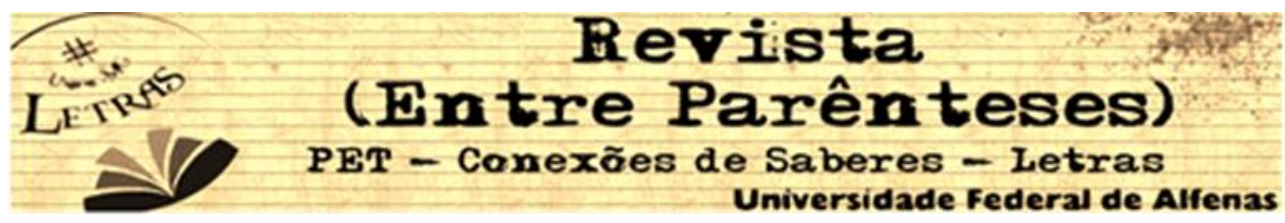

historia, ficción y literatura en textos memorialísticos a través de un abordaje de las consideraciones de Paul Ricoeur (2007), Benedito Nunes (1998), Valéria Gobbi (2004), Márcio Seligmann-Silva (2003) y Sandra Pesavento (2000) acerca del asunto.

Palabras Clave: Memoria; Ficción; Historia; Literatura.

A narrativa de cunho memorialista tem forte tradição no Brasil, pelo menos desde fins do século XIX, com o Romantismo, quando começam a surgir os primeiros textos que se pautam pelo registro de eventos e de recordações relacionados à vida pessoal dos escritores e à sua inserção cultural e identitária na história de nosso país. De acordo com Paulo Bungart Neto (2011), isso se deve, em especial, à emergência de uma "consciência nacional" que se reflete na necessidade de elaboração de uma literatura genuinamente brasileira, para a qual se mostra importante um entendimento dos próprios escritores de seu papel como intelectuais e como artistas e de que modo esse papel se relaciona com a vida política, social e cultural brasileira.

Assim, pautamo-nos pela convicção de que memória, narrativa e história estão, no caso de obras de tradição memorialista, interligadas, não sendo possível definir com clareza as fronteiras que as delimitam ou restringem, o que impossibilita que sejam classificadas e compartimentadas em espécies de "caixas" isoladas. Isso não quer dizer, entretanto, que as tomemos por semelhantes ou sobrepostas, mas que tentamos articulá-las como fios que se entrecruzam, que se encontram, que se separam, que se distanciam e que voltam novamente a se encontrar na tessitura de uma determinada obra. Dessa forma, o objetivo deste artigo é discutir e refletir acerca desses três pontos de aproximação e de distanciamento entre a narrativa memorialística e a narrativa histórica.

Tais entrecruzamentos remetem à discussão acerca da relevância da literatura, a qual remonta à Antiguidade, quando Platão, segundo pondera Márcia Valéria Zamboni Gobbi, afirma que "a arte não passaria de um 'jogo de criança, 


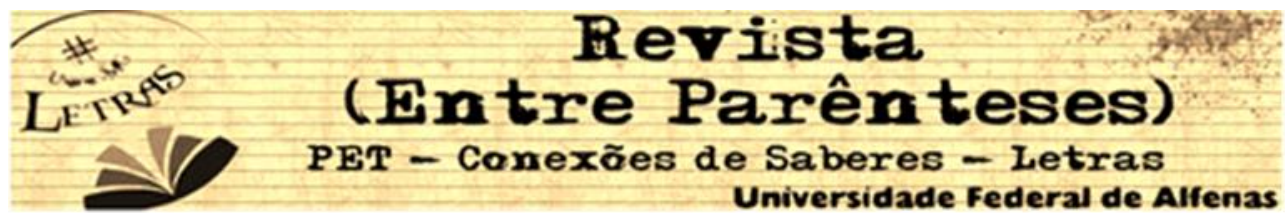

despido de seriedade', que não traz consigo qualquer conhecimento minimamente válido" (GOBBI, 2004, p. 39). Para o filósofo, a arte não deveria ocupar um lugar relevante na sociedade, uma vez que não oferece conhecimento significativo e se apresenta apenas como uma imitação da imitação, afastando, assim, cada vez mais, o indivíduo de alcançar o tão almejado mundo das ideias.

Entretanto, Gobbi (2004) argumenta que é exatamente a partir da articulação entre a criação artística e a realidade que pode preponderar o conhecimento. A pesquisadora defende também que

[...] o poeta é, sim, um artífice, um artesão, porque a criação literária envolve, necessariamente, trabalho, técnica e produto; a arte é, também necessariamente, um simulacro: trabalha com materiais diversos da realidade das coisas e, portanto, só poderia fazer delas uma outra coisa, impondo-Ihes uma forma que não é natural; além disso, ao definir o fazer artístico como um 'jogo de criança', apontase para o aspecto lúdico da criação (o 'prazer do texto'), seu distintivo mais que desejável (GOBBI, 2004, p. 39)

De acordo com a pesquisadora, essa discussão sofre uma importante alteração, ainda na Antiguidade, com as considerações de Aristóteles, para quem a arte se apresenta como uma representação do verossímil e do necessário, ou melhor, ela retrata o que poderia acontecer ou o que poderia ter acontecido. $\mathrm{Na}$ perspectiva aristotélica, na poesia (que equivale à literatura, de forma ampliada), não há a necessidade de se ater apenas à realidade, já que isso é atribuição da história. A poesia não teria, assim, o objetivo de persuadir o leitor de que o fato narrado seja ou não real; pelo contrário, ela visa a entreter e a levar o leitor a refletir sobre sua existência, sobre a sociedade em que vive e sobre tudo aquilo que o rodeia, permitindo-lhe, desse modo, a formação de uma visão mais crítica da realidade.

Ainda recorrendo a Aristóteles, Gobbi indica que as diferenças entre a poesia e a história não se pautam pelo estilo usado para escrevê-las (se o verso ou 


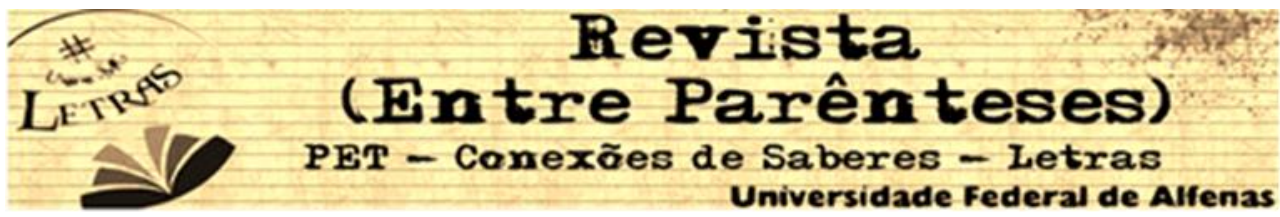

a prosa), mas sim pelo teor de sua escrita: enquanto a história se ocupa com o relato de acontecimentos particulares, específicos, a literatura tem o poder de mostrar verdades consideradas universais, "justamente pelo seu poder de revelar o ilusório do mundo em que vivemos, alcançando, assim, o universal pela mediação do particular. A ficção permitiria desvendar as aparências, levando o homem a conhecer as essências [...]" (GOBBI, 2004, p. 40).

As relações entre a história e a literatura são também um dos principais eixos de investigação da historiadora Sandra Jatahy Pesavento. Em seu texto "Fronteiras da ficção: diálogos da história com a literatura" (2000), por exemplo, reflete sobre a questão a partir da análise do romance Iracema, de José de Alencar, e do texto historiográfico Capítulos da História Colonial, de Capistrano de Abreu, afirmando, em sua argumentação, que tanto os textos históricos comportam recursos ficcionais quanto os textos literários podem ser cercados por estratégias documentais de veracidade. Isso confirmaria o fato de que, quando história e literatura são entrecruzadas, as fronteiras entre esses dois campos de conhecimento e produção são diluídas.

A autora começa seu texto alertando sobre a permanente necessidade de alguns historiadores de diferenciar marcadamente a literatura e a história, na tentativa de diminuir ou desvalorizar aquela em detrimento desta. Seu posicionamento, entretanto, visa a demonstrar que não há necessidade de separar tão rigidamente cada um desses discursos, uma vez que apresentam muitos pontos de interseção. Pesavento (2000) acredita que, assim como a literatura precisa de um narrador para apresentar os fatos narrados, a narrativa histórica necessita também de um narrador para expor o que ouviu, viu ou pesquisou, ou seja, em sua concepção, o que o historiador faz é (re)apresentar os fatos para o leitor. Nesse processo, ele recorta, seleciona e relaciona os fatos que serão apresentados como "verdadeiros", conformando a história de uma sociedade, mas, ao mesmo tempo, 


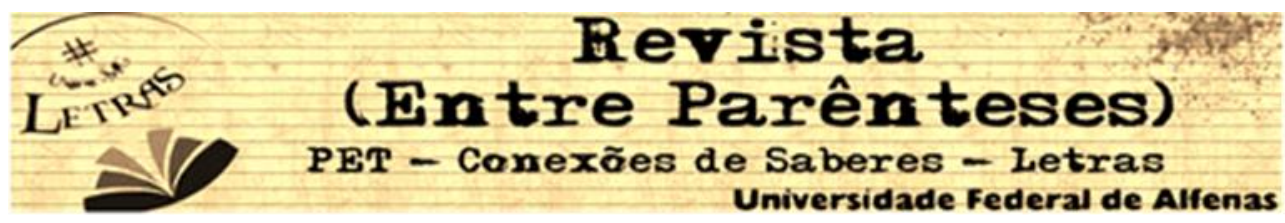

seria possível pensarmos que, ao agir dessa maneira, ele ficcionaliza seu texto, nele enxertando a subjetividade que permeia qualquer construção narrativa:

Que a história é narrativa, bem o sabemos; que o historiador investiga, seleciona e constrói o seu campo, o seu tema e o seu objeto, parece também fora de dúvida. Que o imaginário, esta capacidade de representar o real por um mundo paralelo de imagens, palavras e significados, tem uma força por vezes mais "real" que o próprio "real concreto", é também uma visão que se difunde.

Mas admitir que os historiadores realizam ficção e que não almejam a verdade é ainda considerado por muitos heresia! (PESAVENTO, 2000, p. 37).

Para reforçar sua defesa em relação à necessária ficcionalização que perpassa o texto histórico, Pesavento vale-se também da historiadora Natalie Davis (1989) a qual acredita que o historiador tem necessidade de recorrer à imaginação para construir seu texto histórico e, assim, relacionar todos os fatos/fontes que precisam ser narrados. Dessa forma, Davis (1989, p. 138) entende que o historiador trabalha com a verossimilhança, uma vez que não há como reproduzir a realidade passada, mas apenas "transportar para o papel" - ou seja, narrar - aquilo que já foi vivido, experienciado.

Entretanto, ambas as pesquisadoras reconhecem que esse uso da imaginação, quando pensamos no fazer histórico, é um uso limitado, uma vez que matizado pelos métodos próprios à história, dentre os quais se destaca a importância das "fontes": a ficção no texto histórico "é controlada pelo arquivo, pelo documento, pelo caco e pelos traços do passado que chegam até o presente" (PESAVENTO, 2000, p. 39). Entretanto, se ao historiador não é permitida a criação de vestígios do passado, todavia é ele quem atribui ou confere a esse vestígio sentido histórico, de modo que a recorrência da ficção na história se faz tanto por via da seleção do que será narrado quanto pela forma como o historiador apresenta 


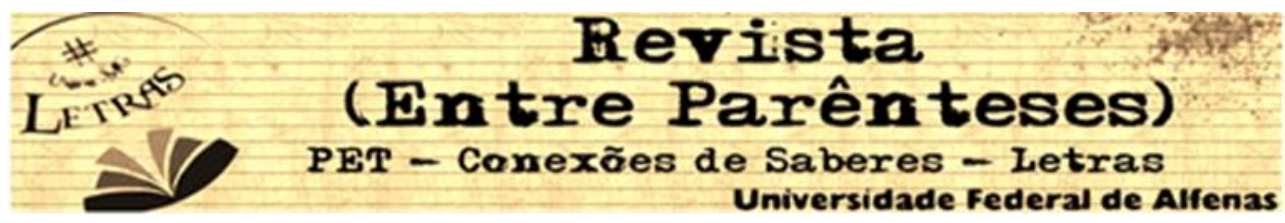

esses vestígios em sua articulação narrativa:

O historiador é obrigado a realizar sempre uma ficção perspectivista da história, dado que é impossível a existência de uma história que recolha simplesmente o passado nos arquivos... Não se chega, pura e simplesmente, a fatos aprioristicamente estabelecidos por fontes. A história é, neste sentido, sempre construção de uma experiência, que tanto reconstrói uma temporalidade quanto a transpõe em narrativa (PESAVENTO, 2000, p. 38-39).

Esse aspecto é também destacado por Márcio Seligmann-Silva (2003), pesquisador que dedica boa parte de suas investigações a reflexões acerca das relações entre memória, história e literatura e que indica como é problemática a visão de alguns historiadores que visam a anular a memória individual e a memória coletiva em detrimento da ilusão de uma retratação "objetiva" do passado, baseada apenas em "fatos". Para ele, a memória possui uma relação mais aberta e afetiva com o passado e por isso intervém e determina boa parte de seus caminhos. Ela não é singular; ao contrário, é plural, na medida em que, na sociedade, apresenta-se sempre um embate em relação às múltiplas leituras acerca do passado: uma vez que cada indivíduo oferece uma versão diferente sobre um mesmo fato o qual foi narrado e vivenciado por outros, não há como existirem relatos exatamente iguais de um mesmo acontecimento, considerando que o registro da memória é seletivo e atua entre a lembrança e o esquecimento. Partindo dessa ideia, o pesquisador acredita que "a tarefa da memória deve ser compartilhada tanto em termos na memória individual e coletiva como também pelo registro (acadêmico) da historiografia" (2003, p. 63). Não há como separar esses elementos que são essenciais seja para a construção da história de um povo, de uma nação, seja para a construção de uma história familiar.

Partindo dessas considerações, é relevante refletir a respeito do lugar da imaginação e da ficção na construção do discurso memorialístico, para o qual 


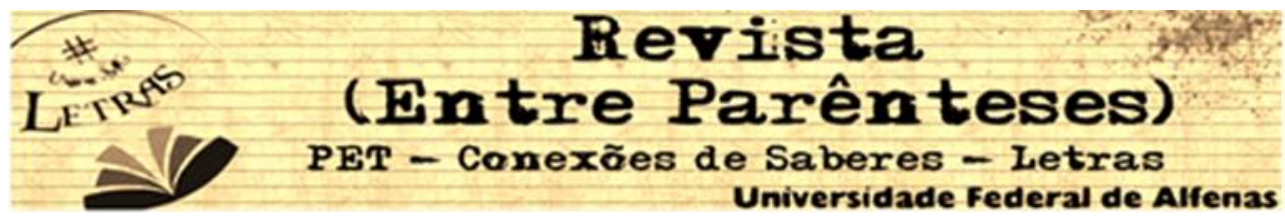

recorremos aos estudos de Paul Ricoeur (2007) e Benedito Nunes (1988) que abordam as relações existentes entre a memória e a ficção na construção de narrativas, passando pelas distinções entre a "narrativa histórica", a "narrativa ficcional" e a "narrativa memorialística".

Benedito Nunes, em seu texto "Narrativa histórica e narrativa ficcional", aborda as distinções entre as formas de construção dessas narrativas. Para ele, as diferenças entre uma e outra remontam à ligação que ambas têm com o mito. Durante a Idade Média, a história era entendida como narração dos feitos históricos e de crônicas que abordavam as lendas da época.

No século XIX, conforme o autor, há a separação entre História-ciência e História-arte, quando foi definido o afastamento entre a pesquisa e a narração. A História-ciência (ou História-pesquisa) equivale a uma história da história que permite acesso ao passado por meio de documentos, de monumentos e de arquivos, transmitindo, assim, um conhecimento imediato e indireto. A História-arte, por sua vez, é entendida pelo filósofo brasileiro como uma narrativa de acontecimentos que recria os fatos passados como se fossem presentes, tornando 0 historiador em um contemporâneo dos fatos narrados e fornecendo, assim, imagens do passado como sendo atuais. Para isso, a narrativa não se eximiria de utilizar a imaginação para projetar tais imagens, que seriam reconstruídas através da narrativa (cf. NUNES, 1988, p. 10-12).

Ele explica, assim, que a História e a Ficção, num primeiro momento, entrosam-se como formas de linguagem objetivando a atividade humana e que a História, ao selecionar, simplificar e organizar os fatos que são relatados, pressupõe algum tipo de imaginação, já que, muitas vezes, o historiador precisa resumir um século em uma página.

Partindo disso, Nunes assegura que a História, a Ciência e a Ficção visam a apresentar os objetos do pensamento humano, estando, assim, ligadas 


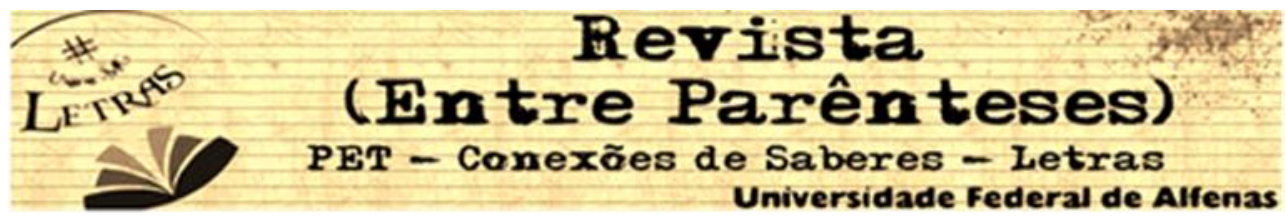

naturalmente:

A História, investigação e registro de fatos sociais das civilizações, recorre a leis gerais, que são próprias à ciência, e também utiliza a ficção; a ciência pode limitar-se ao registro de fatos, e a Ficção, por intermédio do romance, do drama, alcança, honrando a observação aristotélica de que a poesia é "mais filosófica do que a história", um nível de generalidade semelhante ao do pensamento científico (NUNES, 1988, p. 12).

Nunes acredita que a narração - que é vista por muitos como recurso exclusivo da ficção - está presente tanto nos textos ficcionais como nos textos históricos. Mesmo os textos históricos sendo entendidos como científicos, apresentam elementos ficcionais em sua construção na medida em que os eventos, os fatos narrados passam por um processo de recorte, de seleção para constituírem o texto histórico.

As reflexões de Benedito Nunes dialogam diretamente com as proposições do filósofo Paul Ricoeur. Este, em seu livro A memória, a história, o esquecimento, apresenta a relação entre a memória e a imaginação, afirmando que há uma forte associação entre ambas. Para ele, evocar a memória é, por conseguinte, imaginá-la e, logo, lembrar-se dela. Apesar dessa ligação intrínseca, o filósofo explica que a imaginação é considerada inferior na escala dos modos de conhecimento, o que contribui para a redução da importância atribuída à memória pelos estudiosos de ciências.

Na tentativa de distinguir memória e imaginação, Ricoeur (2007) afirma que é possível apontar duas direções opostas, mas que se complementam em um determinado ponto, para a construção da narrativa memorialística. De um lado, teríamos a imaginação que está voltada para o fantástico, para a ficção, para o irreal, para o utópico; de outro, a memória que remete à realidade anterior, ao passado, o qual institui a marca temporal do que é lembrado. Conforme o 


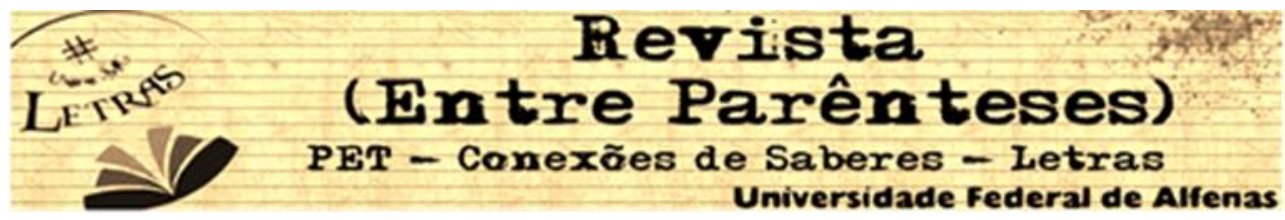

pesquisador, a memória é a garantia de algo que aconteceu antes mesmo da formação da lembrança, e mesmo a historiografia não poderia deixar de convir que a memória é uma referência ao passado, ao que de fato aconteceu, embora ela se utilize da imaginação para a consecução de seu objetivo principal, que é evocar esse algo que já passou.

Além disso, Ricoeur aponta que tanto a imaginação quanto a memória não podem se esquivar do esquecimento, o qual é entendido como "apagamento dos rastros e como falta de ajustamento da imagem presente à impressão deixada como que por um anel de cera" (RICOEUR, 2007, p. 27) e que se apresenta como companheiro inseparável de ambas.

O esquecimento, na perspectiva ricoeuriana, poderia ser tomado como um não esforço para recordar: sempre há a tentativa de evocar aquilo que possa ter sido esquecido e a recordação seria exatamente aquilo que não foi esquecido. Não há, segundo Ricoeur, uma distinção definitiva sobre o surgimento do esquecimento, que poderia ter sido originado de duas formas: pelo apagamento definitivo ou pelo impedimento provisório do que foi aprendido antes.

É relevante pensar ainda, de acordo com Ricoeur, a ideia de continuidade do tempo nos processos de evocação da memória: esta é evocada no presente que retoma algo que ficou no passado, entretanto o presente torna-se passado e assim as lembranças vão se acumulando mutuamente em um passado profundo.

Para o filósofo, é necessário pensar a memória como certa, pois a memória é a única maneira de retomar e relembrar o passado, ainda que exista a relação dela com a imaginação, algo subjetivo e de credibilidade questionável. É justamente por essa característica de não ser totalmente confiável, devido a sua ligação com a imaginação, que a memória possibilita o único caminho para conferir autenticidade ao que se declara como lembrança.

Ainda segundo Ricoeur, existem três tipos de narrações: as narrações que Revista (Entre Parênteses)

Volume 2, Número 5, 2016 - ISSN 2238-4502 


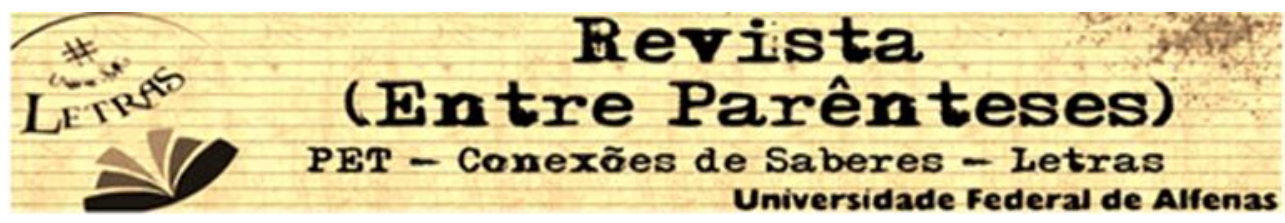

visam retomar lembranças, as narrações fictícias e as narrações que tendem a representar o passado. As narrações que buscam a representação sempre receberão mais importância em relação às outras duas, uma vez que oferecem uma falsa ilusão de que estão retratando verdadeiramente o que já aconteceu. Contudo, de acordo com suas considerações, é possível concluir que não há como retratar fielmente algo que já aconteceu, que ficou no passado, uma vez que, ao tentar reconstruir a imagem de uma lembrança, ela não será completamente fiel ao que de fato ocorreu, isto é, a reconstrução dessa lembrança contará com a imaginação para complementar os traços que foram apagados pelo tempo. O traço diferencial entre memória e imaginação, então, é a limitação fictícia a que a memória está destinada. (cf. RICOEUR, 2007, p. 25-70).

Tecidas essas considerações acerca das relações entre as narrativas histórica, ficcional e memorialística, procuraremos refletir um pouco mais sobre as últimas, que nos interessam mais especificamente, buscando entender como elas são abordadas nas próprias reflexões literárias. Conforme a pesquisadora Maria Lúcia Dias Mendes que se dedicou, em sua tese de doutorado, a estudar o texto memorialístico de Alexandre Dumas,

[...] o termo "memórias" [...] está tradicionalmente ligado às narrativas de vida, desde a origem das línguas romanas. Um mémoire é, a princípio, um relato de fatos, a exposição de um tema. O termo "Mémoires", no plural, está ligado à recapitulação, à inscrição em mémoire de acontecimentos aos quais o autor teve acesso direto e que possibilitam a sua rememoração. O memorialista não é um historiador, nem um cronista apenas, trata-se, na verdade, de uma testemunha da História. Seu testemunho restringe-se aos acontecimentos ao quais ele esteve ligado - como ator ou expectador (sic). Para escrever, o autor normalmente recorre a testemunhos de outras pessoas presentes ou mesmo a fontes documentais; contudo é a primeira pessoa que toma a frente na narração, organizando os fatos de acordo com a perspectiva pessoal de um indivíduo em particular (MENDES, 2007, p. 37-38). 


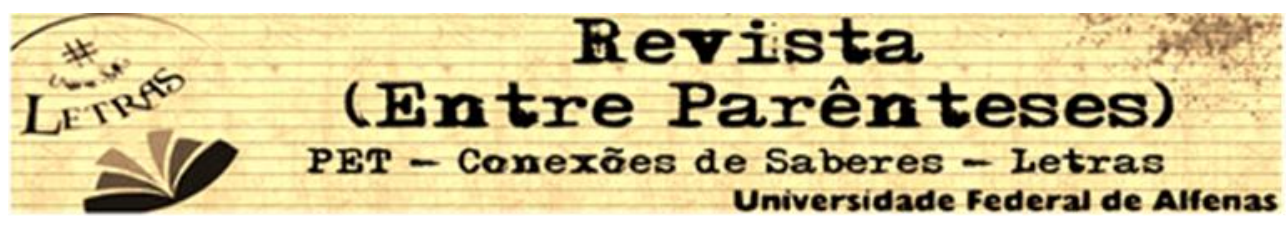

Dessa forma, Mendes (2007) pontua que o memorialismo corresponde às narrativas de vida e que é um conceito que remonta à Roma Antiga, devido à origem da palavra memória. Conforme essa perspectiva, a função de um escritor de memórias não seria retratar o passado e, assim, fazer as vezes de um historiador; pelo contrário, o memorialista narraria as suas lembranças a partir do que viu e do que ouviu, moldando sua narrativa com o que aprendeu, entendeu e interpretou de toda a sua vivência.

Tomadas, portanto, como "memórias" ou "memorialismo", as narrativas memorialísticas movimentam-se, conforme afirma Massaud Moisés no verbete "Memórias", de seu Dicionário de termos literários (2013), no espaço ocupado pela autobiografia, pelo diário e pelas confissões. As memórias, entretanto, distinguem-se por se constituírem como narrativas em primeira pessoa do singular, objetivando a reconstrução do passado a partir dos acontecimentos vivenciados pelo narrador. Nessa perspectiva, no texto de cunho memorialístico, o autor seleciona os acontecimentos que serão narrados de acordo com a importância que cada um desses eventos tem para ele mesmo, de modo que o texto memorialístico apresenta uma forte subjetividade, que o faz pender mais para o lado da narrativa ficcional que para o lado da narrativa histórica, na medida em que sua principal preocupação, ao narrar memórias pessoais, é retratar suas impressões dos fatos e não focar estritamente nesses fatos.

A narrativa memorialística - que não se preocupa em seguir a linearidade do tempo - é construída, assim, com a apreensão de experiências julgadas importantes por parte do autor, não apenas como sujeito de uma existência marcada por episódios pitorescos e incomuns, mas também pelas impressões deixadas pelos outros em sua memória. Isso implica que a veracidade desses eventos é mais vivencial do que documental, isto é, "o subjetivismo, congenial às modalidades 


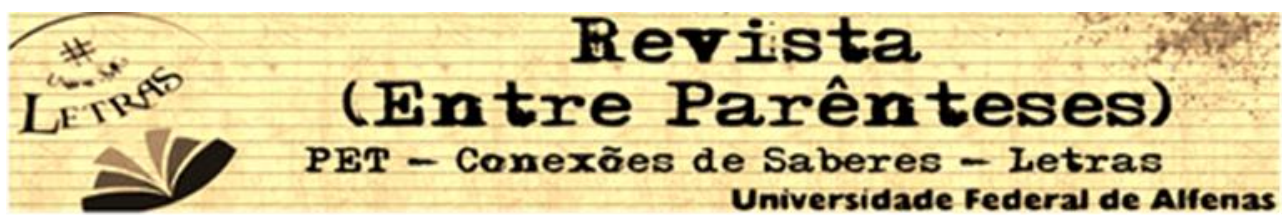

autobiográficas vizinhas, alcança neste caso suma intensidade, aproximando-se ainda mais do terreno ocupado pela narrativa ficcional ou pelo lirismo" (MOISÉS, 2013, p. 289). Moisés assegura ainda que "distorcido pela memória o passado transfigura-se como se parecesse inventado, uma vez que o intuito reside menos no pacto autobiográfico estrito do que na reconstituição das lembranças que restaram do fluxo e refluxo dos dias" (MOISÉS, 2013, p. 289).

Sueli Gedoz e Terezinha da Conceição Costa-Hubes, em seu texto "A leitura do gênero discursivo memórias literárias a partir de um olhar bakhtiniano" (2010), defendem que a narrativa memorialística visa a resgatar o passado de alguém por meio das recordações vivenciais desse mesmo alguém. Entretanto, elas ponderam que o autor de um texto memorialístico busca "representar a realidade por meio de sua visão e interpretando aspectos que considera mais importantes, sem uma preocupação em retratá-los de modo fiel" (GEDOZ, COSTA-HUBES, 2010, p. 264).

Dessa forma, entende-se que o texto memorialístico apresenta, em sua constituição, expressões pessoais do autor e que este, por sua vez, ainda que construa sua narração a partir de acontecimentos reais de sua vida, de experiências pelas quais realmente passou, costura-as juntamente a sua perspectiva pessoal e ficcional.

Seguindo essa linha de pensamento, Maria Lúcia Aragão (1992) afirma, em "Memórias literárias na modernidade", que

Hoje em dia costumamos chamar de "memórias" de um personagem a narrativa feita por ele mesmo dos acontecimentos de sua vida, com uma insistência sobre os acontecimentos objetivos, mais do que sobre o vivido subjetivo. [...]

$\mathrm{Na}$ elaboração literária de uma vida, o autor realiza um incessante diálogo entre o passado e o presente, colocando em cena a elaboração de seu ser pessoal, na procura das significações contidas nos fatos passados. Diríamos que o memorialismo faz uma segunda leitura do tempo vivido ou... perdido (ARAGÃO, 1992, s/p). 


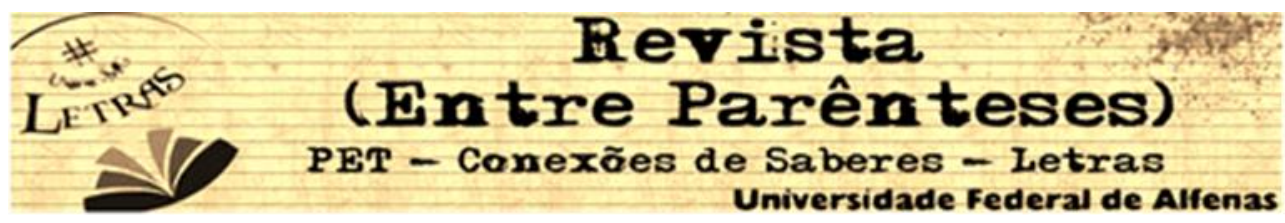

Percebe-se, assim, que as narrativas memorialísticas não possuem 0 objetivo de constituir um retrato fiel da realidade, sendo seu interesse maior narrar sobre os acontecimentos que, de alguma forma, foram importantes na vida do narrador e daqueles que compõem seu círculo social, como família e amigos. Em virtude disso, Aragão acredita que

Quando lemos uma história de vida, devemos estar sempre conscientes de que o autor nos conta apenas uma parte de sua história, que escolhe os fatos de maneira a nos apresentar uma certa imagem elaborada de si. [...] A narrativa de vida não se prende à descrição exata dos fatos. Ela obedece, isso sim, à exigência de fidelidade a si mesmo, segundo a ordem dos valores reveladores do sentido de uma vida, na plenitude de sua permanente atualidade (ARAGÃO, 1992, s/p).

A pesquisadora explica que o termo "memórias", a partir do século XVII, passou a ser usado para denominar os textos de historiadores ou de indivíduos que não seguiam a carreira literária - memórias de parlamentares, nobres, religiosos, militares - prevalecendo, dessa forma, o interesse pela informação ou pelo testemunho de algum fato. Mais tarde, o termo "memórias" foi destinado às narrativas autobiográficas e, a partir daí, as narrativas históricas cederam lugar à narrativa de experiências pessoais. Desse modo, a elucidação de uma vida privada, misturada a acontecimentos coletivos, interessa mais ao leitor pelo seu lado anedótico do que por sua fidelidade aos fatos reais.

Isso ocorre, uma vez que, ainda de acordo com Aragão,

um livro de memórias é sempre uma nova forma de apreensão dos fatos, antes isolados, mas agora reunidos, que compuseram a trama de uma vida, fatos esses que voltam ao presente, através da lembrança, provando que alguma marca tiveram no conjunto do vivido. Outros fatos ficaram necessariamente enterrados, e o recurso 


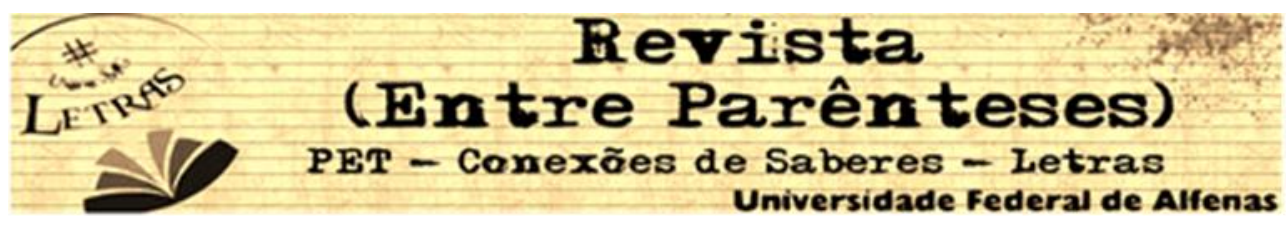

é imaginar, não o que realmente aconteceu, mas o que poderia ter acontecido.

Um livro de memórias é sempre uma segunda chance de se viver o que já se viveu, de viver o que não se viveu e de se recuperar o "tempo perdido". (ARAGÃO, 1992, s/p).

A narração de memórias é, portanto, uma experiência de recordação do autor, na medida em que precisa voltar ao seu passado e reviver, relembrar tudo aquilo que havia ficado para trás. Ao fazer essa viagem, o autor/narrador escolhe tanto os acontecimentos que marcaram sua trajetória de vida e que deseja trazer à tona no que diz respeito à melhor maneira de apresentar esses fatos. Afinal, a escrita de memórias pode funcionar como uma nova forma de viver o passado, uma oportunidade para se reescrever uma história acrescentando ou retirando dela aquilo que interessa ou não ao narrador ser conhecido por terceiros. O autor, nessa perspectiva, é o senhor de seu passado, determinando ele próprio a construção e a consolidação de suas memórias.

Corroborando essa ideia, a pesquisadora Patrícia de Cássia Pereira Porto assegura, em seu artigo "Narrativas memorialísticas: memórias e literatura" (2011), que, em nossas lembranças - um espaço que sempre percorremos -, sempre haverá a relação entre o que aconteceu e o que sonhamos ter acontecido. Isso porque as pessoas que possuem a capacidade de lembrar detalhadamente os fatos que marcaram sua vida são as mesmas que conferem "alma" a essas lembranças e que, ao fazer isso, atribuem à memória sua afetividade, seus desejos e seus interesses, enfim, preenchem de subjetividade suas narrações. Porto defende, portanto, que "a escrita memorialística é uma escrita que passeia entre os fatos e os devaneios, entre as imagens da imaginação e da memória, entre os tempos pretéritos e o desejo do tempo futuro" (PORTO, 2011, p. 202).

Além dessa linha argumentativa que aponta as relações entre "história" e "imaginação" na constituição do texto memorialístico, vários estudos dedicam-se a 


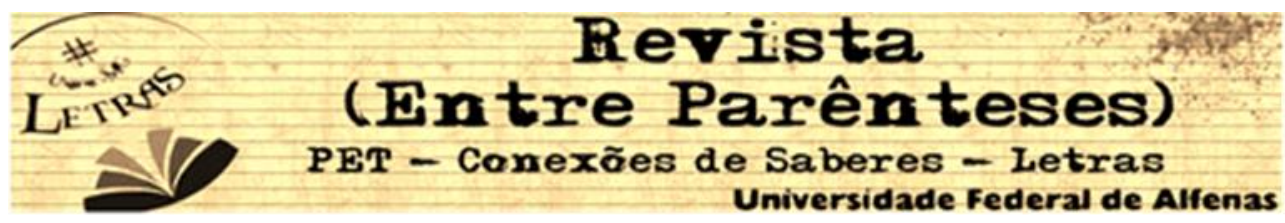

compreender os motivos os quais fazem com que esse tipo de narrativa atraia, cada vez mais, o público leitor. Essa é uma das questões apontadas por Valéria Brisolara, no artigo "Narrativa, memória e identidade: o boom das narrativas de cunho memorial": a pesquisadora acredita que o crescente interesse em textos memorialísticos, assim como em todos os tipos de textos confessionais, os quais apresentam o cotidiano particular de seus autores, deve-se ao fato de ser esse o tipo de escrita que mais se aproxima do leitor, na medida em que, nesse tipo de obra, o leitor tem contato com um eu - uma pessoa "viva", "real" - que lhe abre sua vida e suas mais íntimas confidências. Nessa perspectiva, a leitura do texto confessional criaria uma área de contato entre o leitor e o autor, possibilitada por meio da partilha dos medos, das alegrias, dos sonhos, das incertezas, levando o leitor a um reconhecimento e, até mesmo, a um certo conforto em poder dividir com o autor, de forma silenciosa e íntima, suas incertezas e seus medos.

Mas, mesmo ressaltando essa possibilidade, Brisolara (2012) assegura que é de fundamental importância atentar para o fato de que o sujeito narrador é um efeito de linguagem e que, jamais, autor e narrador serão a mesma pessoa, pois narrar é constituir-se como um sujeito-personagem, isto é, narrar é construir uma nova identidade. Diante disso, ela afirma que, a partir de suas pesquisas, pode perceber que a veracidade dos fatos narrados em textos memorialísticos não tem qualquer relevância para construção da narração, destacando-se antes a forma como são percebidos e apresentados pelo autor. A pesquisadora assegura, assim, que o interesse pelas memórias extrapola as barreiras da literatura, alcançando outras manifestações artísticas e outros meios de divulgação, como os filmes, que estão também colocando as memórias no centro das discussões cinematográficas.

Para concluir nossas reflexões sobre o memorialismo e encerrar este artigo, optamos por recorrer a um estudo dedicado àquele que é considerado o mais importante memorialista brasileiro: Pedro Nava. No livro Espaços da memória: um 


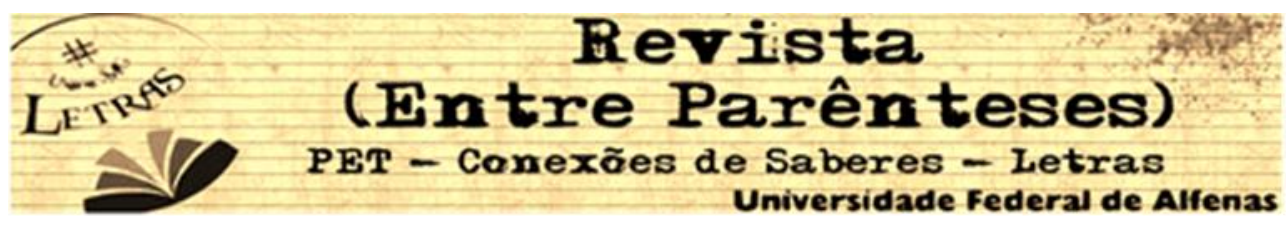

estudo sobre Pedro Nava, Joaquim Alves de Aguiar faz a seguinte afirmação, recorrendo a duas obras do próprio escritor mineiro, Balão Cativo (de 1973, indicada por "BC") e Chão de Ferro (de 1976, indicada por "CF"):

[...] [Pedro Nava] sabia que recordar é sobrepor ao passado o presente, com sua acumulação de outros tempos passados, ou seja, de experiências. Essa característica da recordação abre caminho para a imaginação criadora, que transfigura 0 acontecimento lembrado: "É impossível restaurar o passado em estado de pureza. Basta que ele tenha existido para que a memória o corrompa com lembranças superpostas" (BC, p. 221).

Quanto mais recuado, mais imperfeito é o tempo e maior sua necessidade de ser retocado, aperfeiçoado "por lembranças análogas ou congêneres de sucessos posteriores, que vão tornando o pretérito rico como as pérolas que ganham mais oriente quanto mais usadas, saliente, como os relevos das estátuas avivadas pelo arbítrio da pátina e do polimento dado pelo vento" (CF, p. 192) (AGUIAR, 1998, p. 21).

Corroborando com o que foi discutido anteriormente, Aguiar (1998), a partir das palavras de Pedro Nava, acredita que, ao narrar suas memórias, o autor retomará lembranças e fatos do passado, mas permeados por sua experiência de vida e pela visão de mundo que possui no momento da escrita de suas recordações. Nota-se, assim, mais uma vez, a impossibilidade de se retratar fielmente um acontecimento que ficou no passado e a consciência que a esse respeito tem o próprio escritor. A imaginação tem a função de retocar, de completar as lacunas que foram aparecendo e aumentando com o passar do tempo, pois as lembranças estão sempre sujeitas ao trabalho do esquecimento.

Aguiar explica ainda que, no processo de recordação para escrever suas memórias, Pedro Nava procedia "como quem exuma os ossos dos cadáveres para examinar as marcas da vida que os mantinha. Daí o título de Baú de Ossos, por exemplo" (AGUIAR, 1998, p. 17). Ao abrir o baú de suas lembranças, o memorialista 


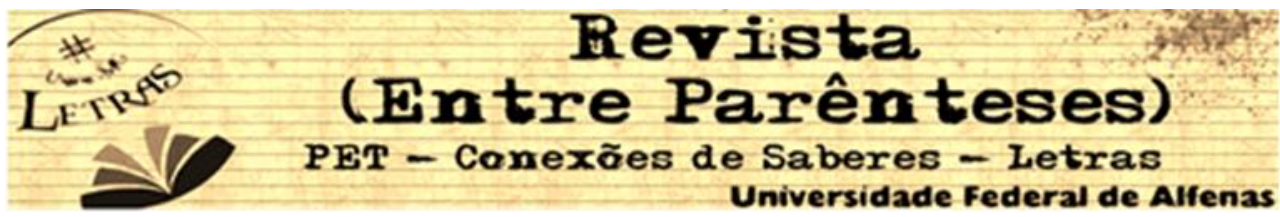

trazia os mortos de sua história novamente à vida e, ao transportá-los para a escrita, fazia com que revivessem. Nessa perspectiva, o pesquisador aponta que, "para Nava, rememorar é dar vida aos desaparecidos no tempo, assim como escrever sobre eles é convertê-los em matéria literária” (AGUIAR, 1998, p. 17-18), ou seja, transformá-los em personagens ficcionais.

É notável, na pesquisa de Aguiar, a preocupação em recorrer a argumentos do próprio Nava para definir o escritor de memórias, o qual, para este, usa elementos da lembrança e da ficção sem saber afirmar exatamente em que momento começa uma e terminam as outras, talvez por que elas sejam inseparáveis. Segundo o pesquisador, Nava entendia a escrita de memória como uma "reconstrução do passado com a ajuda dos dados do presente, rompimento da matéria rememorada com o encadeamento cronológico, descompromisso com o relato verídico" (AGUIAR, 1998, p. 22), ou seja, como uma construção em terreno híbrido, tal qual a narrativa de Nava em que os fatos da realidade são aproximados do tijolo e da pedra, elementos que o escritor trabalharia juntamente à areia e ao cal, por ele manipulados, para constituir uma parede, uma casa ou qualquer outro tipo de construção.

Joaquim Alves de Aguiar, ampliando sua reflexão para os estudos dedicados ao memorialismo, acredita que o fato de abarcarem história e ficção dificulta o seu enquadramento nos gêneros canônicos:

Certamente, tanto os manuais de história quanto os de literatura não costumam dar destaque aos memorialistas. Num campo e noutro, talvez o gênero seja considerado menor, um subgênero, pelo subjetivismo das impressões, prejudicial à objetividade que se espera do historiador; pela adesão ao retrato, que pode empobrecer o texto ficcional. No campo da crítica literária, o maior problema foi sempre medir os graus entre verdade e verossimilhança no discurso memorialístico. Em princípio, mais próximas do verídico que os demais gêneros, com muito de testemunho e de confissão, as 


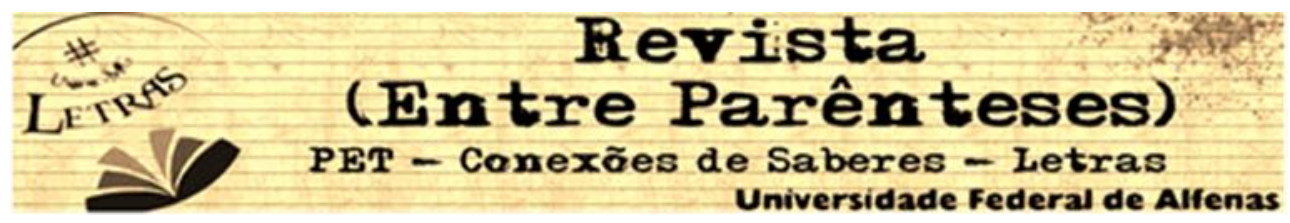

memórias acabaram sendo catalogadas numa espécie de gênero próprio, menor entre os maiores, o "memorialismo", através do qual vêm logrando o reconhecimento do seu estatuto literário (AGUIAR, 1998, p. 23).

Apesar desse impasse em relação à classificação das memórias como gênero, de acordo com Aguiar, Nava não tinha dúvidas sobre sua inclusão no universo literário, o que confirma citando uma passagem do autor publicada em Círio Perfeito, obra de 1983:

[...] tudo isso, biografia, história, lembrança e memória não pode ser literatura? Sim. E literatura quando escrita com a surpresa e o mistério da poesia. Com as qualidades da clareza do estilo original. As discussões daquelas diferenças não conduzem a nada. [...] É ocioso discutir os limites da literatura. Literatura é tudo aquilo feito com bom estilo, tudo que é bem escrito e que é tocado, ainda que de leve, pela mão da poesia (NAVA apud AGUIAR, 1998, p. 23).

Na perspectiva de Nava, portanto, o que difere o escritor de memórias que atua no campo da história daquele que atua no campo literário é a forma como ele trabalha com o evento evocado. Isto é, tanto o historiador quanto o memorialista vão reconstruir algo que ficou no passado, entretanto o primeiro apenas descreve objetivamente o evento em questão, ao passo que o segundo visa a traduzir a emoção que o fato the provocou, o que confere ao texto do memorialista sua veia primordialmente ficcional.

As narrações memorialísticas caminham, portanto, como se percebe nos mais diversos estudos sobre o tema, em uma linha tênue que separa história e ficção, uma vez que visam a retomar, a posteriori, algo que já foi vivido e que, de alguma forma, marcou a experiência de alguém. Como a memória não é exata, marcando-se tanto pelo esquecimento quanto pelos afetos, ao retomá-la na construção de uma "escrita de si", certamente será necessário recorrer à 


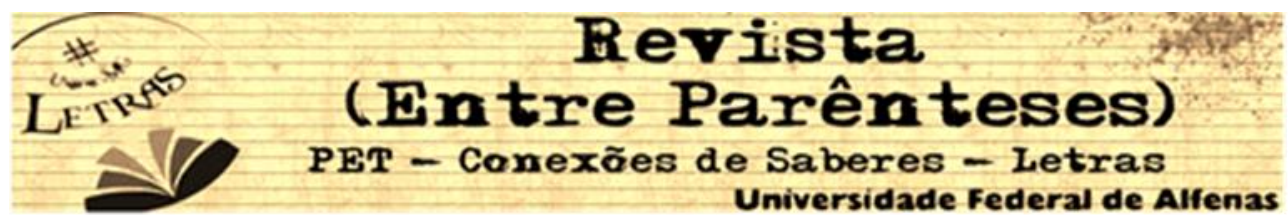

imaginação.

\section{REFERÊNCIAS}

AGUIAR, Joaquim Alves de. Introdução. In: AGUIAR, Joaquim Alves de. Espaços da memória: um estudo sobre Pedro Nava. São Paulo: Editora da Universidade de São Paulo, 1998. p. 13-26.

ARAGÃO, Maria Lucia. Memórias literárias na modernidade. Letras, Santa Maria, n. 3, jan./jun. $1992 . \quad$ Disponível em: <http://cascavel.ufsm.br/revistas/ojs2.2.2/index.php/letras/article/view/11423/6898>. Acesso em: 10 ago. 2015.

BRISOLARA, Valéria. Narrativa, memória e identidade: o boom das narrativas de cunho memorial. Cenários, Porto Alegre, v. 1, n. 5, 2012. Disponível em: $<$ http://seer.uniritter.edu.br/index.php/cenarios/article/view/737/499>. Acesso em: 03 set. 2016.

BUNGART NETO, Paulo. De Taunay a Nava: grandes memorialistas da literatura brasileira. In: ENCONTRO DIÁLOGOS ENTRE LETRAS, 1, 2011, Dourados, MS. Anais... p. 44-55. Dourados: UFGD, 2011. Disponível em: <http://www.ufgd.edu.br/eventos/edel/trabalhos/BUNGART\%20NETO,\%20Paulo.pdf >. Acesso em: 03 set. 2016.

FARIAS, Sônia L. Ramalho de. Memorialismo, autobiografia e narrador pósmoderno: a prosa literária brasileira na leitura de Silviano Santiago. Iris, Recife, v. 1, n. 1 p. $\quad$ 67-76, $2012 . \quad$ Disponível em: <http://www.repositorios.ufpe.br/revistas/index.php/IRIS/article/view/12/11>. Acesso em: 03 set. 2016.

GEDOZ, Sueli; COSTA-HUBES, Terezinha da Conceição. A leitura do gênero discursivo memórias literárias a partir de um olhar bakhtiniano. Signum: estudos da linguagem, Londrina, v. 13, n. 2, p. 253-273, 2010. Disponível em: <http://www.uel.br/revistas/uel/index.php/signum/article/view/6528/6978>. Acesso em: 03 set. 2016.

GOBBI, Márcia Valéria Zamboni. Relações entre ficção e história: uma breve revisão teórica. Itinerários, Araraquara, v. 22, p. 37-57, 2004. Disponível em: <http://seer.fclar.unesp.br/itinerarios/article/view/2736/2473>. Acesso em: 03 set. 


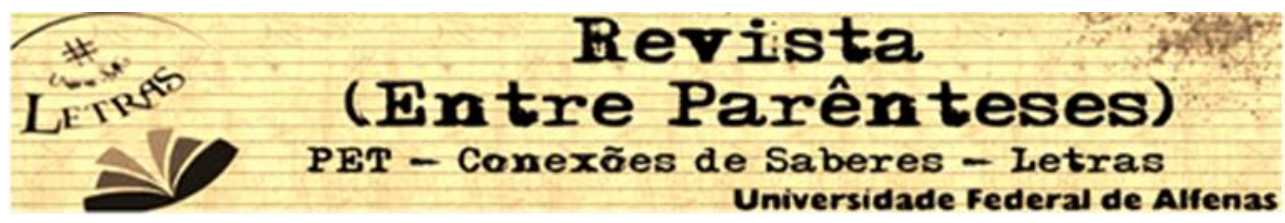

2016.

MENDES, Maria Lúcia Dias. No limiar da história e da memória: um estudo de Mes mémoires, de Alexandre Dumas. 2007. 320 f. Tese (Doutorado em Letras Modernas) - Faculdade de Filosofia, Letras e Ciências Humanas, Universidade de São Paulo, São Paulo. Disponível em: <http://www.teses.usp.br/teses/disponiveis/8/8146/tde-01112007-143905/pt-br.php>. Acesso em: 28 ago. 2016.

MOISÉS, Massaud. Memórias. In: MOISÉS, Massaud. Dicionário de termos literários. 12. ed. São Paulo: Cultrix, 2013. p. 289.

NUNES, Benedito. Narrativa histórica e narrativa ficcional. In: RIEDL, Dirce Côrtes (Org.). Narrativa: ficção e história. Rio de Janeiro: Imago, 1988. p. 9-35.

PESAVENTO, Sandra Jatahy. Fronteiras da ficção: diálogos da história com a literatura. Revista de História das Ideias, Coimbra, v. 21, p. 33-57, 2000. Disponível em: <http://rhi.fl.uc.pt/vol/21/spesavento.pdf>. Acesso em: 03 set. 2016.

PORTO, Patrícia de Cássia Pereira. Narrativas memorialísticas: memória e literatura. Revista Contemporânea de Educação, Rio de Janeiro, n. 12, p. 195-211, 2011. Disponível em: <https://revistas.ufrj.br/index.php/rce/article/view/1648/1496>. Acesso em: 03 set. 2016.

RICOEUR, Paul. Da memória e da reminiscência. In: RICOEUR, Paul. A memória, a história, o esquecimento. Tradução Alain François. Campinas: Editora Unicamp, 2007. p. 25-142.

SELIGMANN-SILVA, Márcio. História, memória, literatura: o testemunho na Era das Catástrofes. Campinas: Ed. UNICAMP, 2003.

Recebido em: 15/12/2016

Aceito em: 13/01/2017 